\title{
Glycogen synthase kinase $3 \alpha$ and $3 \beta$ have distinct functions during cardiogenesis of zebrafish embryo
} Huang-Chieh Lee ${ }^{1}$, Jen-Ning Tsai ${ }^{2}$, Pei-Yin Liao ${ }^{1}$, Wei-Yuan Tsai ${ }^{1}$, KaiYen Lin ${ }^{1}$, Chung-Cheng Chuang ${ }^{3}$, Chi-Kuang Sun ${ }^{3}$, Wen-Chang Chang ${ }^{4,5}$ and Huai-Jen Tsai*1

Address: ${ }^{1}$ Institute of Molecular and Cellular Biology, National Taiwan University, NO. 1, Roosevelt Road, Sec. 4, Taipei 106, Taiwan, ${ }^{2}$ School of Medical Laboratory and Biotechnology, Chung Shan Medical University, Taichung 402, Taiwan, ${ }^{3}$ Graduate Institute of Photonics and Optoelectronics and Department of Electrical Engineering, National Taiwan University and Research Center for Applied Sciences, Academia Sinica, Taipei 10617, Taiwan, ${ }^{4}$ Institute of Biochemical Sciences, National Taiwan University, Taipei 106, Taiwan and ${ }^{5}$ Institute of Biological Chemistry, Academia Sinica, Nankang 115, Taiwan

Email: Huang-Chieh Lee - allen628@ms35.hinet.net; Jen-Ning Tsai - zgsk3@yahoo.com.tw; Pei-Yin Liao - pei-in@yahoo.com.tw; WeiYuan Tsai-r90243005@ms90.ntu.edu.tw; Kai-Yen Lin-r95b43014@ntu.edu.tw; Chung-Cheng Chuang-ching101@ms9.hinet.net; ChiKuang Sun - sun@cc.ee.ntu.edu.tw; Wen-Chang Chang - bcwchang@ccvax.sinica.edu.tw; Huai-Jen Tsai* - hjtsai@ntu.edu.tw

* Corresponding author

Published: 3 August 2007

BMC Developmental Biology 2007, 7:93 doi:10.1186/147I-213X-7-93
Received: 17 April 2007

Accepted: 3 August 2007

This article is available from: http://www.biomedcentral.com/I47I-2/3X/7/93

(c) 2007 Lee et al; licensee BioMed Central Ltd.

This is an Open Access article distributed under the terms of the Creative Commons Attribution License (http://creativecommons.org/licenses/by/2.0), which permits unrestricted use, distribution, and reproduction in any medium, provided the original work is properly cited.

\begin{abstract}
Background: Glycogen synthase kinase 3 (GSK3) encodes a serine/threonine protein kinase, is known to play roles in many biological processes. Two closely related GSK3 isoforms encoded by distinct genes: GSK3 $\alpha$ (5I $\mathrm{kDa}$ ) and GSK3 $3(47 \mathrm{kDa})$. In previously studies, most GSK3 inhibitors are not only inhibiting GSK3, but are also affecting many other kinases. In addition, because of highly similarity in amino acid sequence between GSK3 $\alpha$ and GSK3 $\beta$, making it difficult to identify an inhibitor that can be selective against GSK3 $\alpha$ or GSK3 $\beta$. Thus, it is relatively difficult to address the functions of GSK3 isoforms during embryogenesis. At this study, we attempt to specifically inhibit either GSK3 $\alpha$ or GSK3 $\beta$ and uncover the isoform-specific roles that GSK3 plays during cardiogenesis.
\end{abstract}

Results: We blocked gsk $3 \alpha$ and gsk $3 \beta$ translations by injection of morpholino antisense oligonucleotides (MO). Both gsk $3 \alpha$ - and gsk3 $\beta$-MO-injected embryos displayed similar morphological defects, with a thin, string-like shaped heart and pericardial edema at 72 hours post-fertilization. However, when detailed analysis of the gsk $3 \alpha$ and gsk $3 \beta$-MO-induced heart defects, we found that the reduced number of cardiomyocytes in gsk $3 \alpha$ morphants during the heart-ring stage was due to apoptosis. On the contrary, gsk $3 \beta$ morphants did not exhibit significant apoptosis in the cardiomyocytes, and the heart developed normally during the heart-ring stage. Later, however, the heart positioning was severely disrupted in gsk $3 \beta$ morphants. bmp 4 expression in gsk $3 \beta$ morphants was upregulated and disrupted the asymmetry pattern in the heart. The cardiac valve defects in gsk $3 \beta$ morphants were similar to those observed in axin I and apc $c^{\text {mcr }}$ mutants, suggesting that GSK3 $\beta$ might play a role in cardiac valve development through the $\mathrm{Wnt} / \beta$-catenin pathway. Finally, the phenotypes of gsk $3 \alpha$ mutant embryos cannot be rescued by gsk $3 \beta$ mRNA, and vice versa, demonstrating that GSK3 $\alpha$ and GSK3 $\beta$ are not functionally redundant.

Conclusion: We conclude that (I) GSK3 $\alpha$, but not GSK3 $\beta$, is necessary in cardiomyocyte survival; (2) the GSK3 $\beta$ plays important roles in modulating the left-right asymmetry and affecting heart positioning; and (3) GSK $3 \alpha$ and GSK $3 \beta$ play distinct roles during zebrafish cardiogenesis. 


\section{Background}

Glycogen synthase kinase 3 (GSK3) encodes a multifunctional serine/threonine protein kinase, which is ubiquitously expressed in organisms ranging from yeasts to mammals [1-3]. GSK3 is, therefore, very important in the cellular signaling network. In addition to playing pivotal roles in the canonical Wnt and PI3K-PKB/AKT pathways, it has been shown to phosphorylate glycogen synthase, eLF2B, NFAT, c-jun, CyclinD1, NF-kB, as well as many others [4]. GSK3 is involved in many biological processes, including cell survival, tumorigenesis, and developmental patterning.

There are two closely related GSK3 isoforms encoded by distinct genes: GSK3 $\alpha$ (51 kDa) and GSK3 $\beta$ (47 kDa) [5]. The difference in size is due to a glycine-rich extension at the N-terminus of GSK $3 \alpha$. GSK3 $\alpha$ and GSK3 $\beta$ are highly homologous within their kinase domains [6]. Homologues of GSK3 isoforms from species as distant from each other as flies, zebrafishes and humans display over $90 \%$ sequence similarity within the kinase domain $[7,8]$.

Despite that GSK3 $\alpha$ and GSK3 $\beta$ share common substrates, their expression patterns, substrate preferences, regulation, and cellular functions are not identical $[1,6,9,10]$. In vitro study reveals that GSK $3 \alpha$ and GSK3 $\beta$ are inactivated by phosphorylation of a specific $\mathrm{N}$-terminal serine residue (Ser-21 in GSK3 $\alpha$; Ser-9 in GSK3 $\beta$ ) catalyzed by either MAPKAP kinase-1/or $\mathrm{p}^{36 \mathrm{~s} 6 \mathrm{~K}}[11,12]$, whereas protein kinase $C$ phosphorylates and partially inhibits GSK3 $\beta$, but not GSK3 $\alpha$ [13]. In humans, only GSK3 $\alpha$ is deactivated by insulin during physiological conditions [14,15], whereas supraphysiological insulin injection in the rat leads to deactivation of both GSK3 $\alpha$ and GSK3 $\beta \quad[15,16]$. Although differential regulations by the two isoforms of GSK3 were proposed, the exact roles of GSK3 $\alpha$ and GSK3 $\beta$ and endogenous targets of such regulation remain to be investigated.

Several groups have identified small-molecule GSK3 inhibitors $[17,18]$. Most drugs bind to the ATP pocket of GSK3 and compete with ATP. However, these inhibitors are not only inhibiting GSK3, but are also affecting CDK kinase ( 2 and 5) and many other kinases. In addition, there appears to be only a single amino acid difference (Glu196 in GSK3 $\alpha$, Asp133 in GSK3 $\beta$ ), making it difficult to identify an inhibitor that can be selective against GSK3 $\alpha$ or GSK3 $\beta$ [19]. This finding is why it is difficult to analyze the exact roles of GSK3 $\alpha$ and GSK3 $\beta$ in vitro and in vivo.

Recent years, numerous studies indicate that GSK3 negatively regulates cardiac hypertrophy [20-22]. Despite that GSK3 $\beta$ functions as a negative regulator of cardiac hypertrophy, GSK3 also plays an important role in regulating cardiac development. Transgenic mice over-expressing GSK3 $\beta$ in the heart have impairments of postnatal cardiomyocyte growth and abnormal cardiac contractile function [23]. In Xenopus, injection of $g s k 3 \beta$ mRNA in embryos induces expression of $\mathrm{Nkx} 2.5$ and Tbx5 [24]. Oral treatment with lithium, a mood-stabilizing drug that is inhibitory for GSK3, in pregnant women showed a higher incidence of congenital heart defects in babies [25-27]. These findings prove that GSK3 might be involved in heart development. Unfortunately, disruption of the $g s k 3 \beta$ gene in mice results in embryonic lethality caused by severe liver degeneration [9], and no report is available to demonstrate that cardiac defects are happened in GSK3 $\beta$ mutants. Thus, whether the roles of GSK3 $\alpha$ and GSK3 $\beta$ in different species are conserved remain to be investigated. Moreover, the roles of GSK3 in cardiac development are still unclear. Also, whether GSK3 $\alpha$ and GSK3 $\beta$ play similar roles in heart development is ambiguous.

We have previously identified two zebrafish homologues related to mammalian GSK3: zebrafish GSK3 $\alpha$ and GSK3 $\beta$ [8]. In this report, we have taken advantage of the zebrafish system to address the distinct roles of GSK3 $\alpha$ and GSK3 $\beta$ during heart development of zebrafish. Our findings suggest that, in zebrafish, GSK3 $\alpha$, but not GSK3 $\beta$, is necessary in cardiomyocyte survival; whereas the GSK3 $\beta$ isoform plays important roles during zebrafish cardiogenesis, modulating the left-right asymmetry and affecting heart positioning.

\section{Results \\ Knockdown of gsk $3 \alpha$ and gsk3 $\beta$ display similar heart defects in the embryos}

To address the role of GSK3 during zebrafish cardiogenesis, we designed $g s k 3 \alpha$ - and $g s k 3 \beta$-MO for specifically inhibiting the translation of $g s k 3 \alpha$ and $g s k 3 \beta$, respectively. When the protein lysate was extracted from $g s k 3 \alpha$ - and gsk3 $\beta$-MO-injected embryos at 24 hours postfertilization (hpf), Western blot analysis was performed by using isoform-specific antibodies. Results showed that the protein levels of GSK3 $\alpha$ and GSK3 $\beta$ were largely reduced in the protein extracts from $g s k 3 \alpha$ - and gsk $3 \beta$-morphants, respectively (Fig. 1), suggesting that the MOs we designed in this study were isoform-specific.

Similar morphological defects of the heart were observed in $g s k 3 \alpha$ - and $g s k 3 \beta$-MO-injected zebrafish embryos at 72 hpf, such as a thin and string-like shape, pericardial edema, and blood pooling (Fig. 2F, G, I, J). These defects occurred initially in some 2 days postfertilization (dpf) morphants, and then were predominantly observed in most 3- and 4-dpf morphants. Although the heart defects were similar between $g s k 3 \alpha$ - and $g s k 3 \beta$-MO-injected zebrafish embryos, the defects of the gsk $3 \alpha$ morphants were more severe than those of the gsk $3 \beta$ morphants (Fig. 


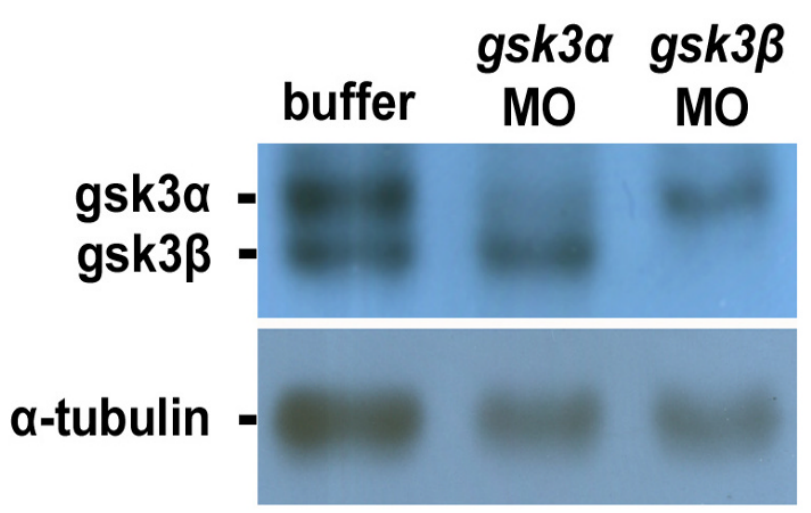

\begin{abstract}
Figure I
Injection of translation inhibitors gsk3 $\alpha$ - and gsk3 $\beta$ $M O$ into embryos can specifically reduce the protein levels of GSK $3 \alpha$ and GSK3 $\beta$, respectively. The total protein lysate extracted from seven zebrafish embryos at 24 hpf was loaded on each lane and analyzed by western blot. The antibody used is indicated in the left of each blot. AntiGSK 3 antibody enables to recognize both GSK $3 \alpha$ and GSK $3 \beta$ proteins; anti- $\alpha$-tubulin antibody was used as a loading control. The protein levels of GSK $3 \alpha$ and GSK $3 \beta$ were reduced greatly in the protein lysates extracted from the gsk3 $\alpha$ - and gsk3 $\beta$-MO-injected embryos, respectively.
\end{abstract}

2B, C, F vs. 2D, G). Around $40 \%$ of the gsk3 $\alpha$ morphant defects were lethal due to an absent body axis during 24 hpf (Fig. 2B), and the remainder of the surviving gsk3 $\alpha$ morphants suffered from an incomplete formation of axis (Fig. 2C), suggesting that $g s k 3 \alpha$ and $g s k 3 \beta$ may function differently during cardiogenesis, although they cause similar heart defects. We also noticed that the percentage of heart abnormalities was dependent on the concentration of the injected $g s k 3 \alpha$ - and $g$ sk3 $\beta$-MO (Table 1 ). When 0.5 ng of $g s k 3 \alpha-\mathrm{MO}$ was injected into 1 -celled stage embryos, we found that $41.8 \%(n=146)$ of embryos displayed a string-like-shape heart; whereas when $2 \mathrm{ng} g s k 3 \alpha-\mathrm{MO}$ were injected, $88.2 \%(\mathrm{n}=212)$ of embryos appeared similar heart defect. Similarly, 2 ng gsk3 $\beta$-MO caused $30.2 \%$ $(n=126)$ of embryos to suffer a string-like-shape heart at 72 hpf; whereas 6 ng gsk3 $\beta$-MO caused $87.5 \%(\mathrm{n}=288)$ of embryos to have similar heart defect. These results indicated that the effect of gsk3-MO on embryogenesis was dosage-dependent and specific.

\section{Heart defects caused by gsk $3 \alpha$ - and gsk $3 \beta-M O$ are induced differently}

We investigated whether the MO-induced defects could be rescued by co-injecting synthetic $g s k 3 \alpha$ or $g s k 3 \beta$-mRNA with its corresponding MOs, and vice versa. Results showed that co-injection of $g s k 3 \alpha-\mathrm{MO}$ with synthetic $g s k 3 \alpha$-mRNA could effectively rescue the defects caused by the injection of $g s k 3 \alpha-\mathrm{MO}$ alone (Table 1 ). Similarly, the gsk3 $\beta$-MO-induced defects were rescued by injection of gsk3 $\beta$-mRNA. However, the synthetic gsk3 $\alpha$-mRNA did not rescue the gsk3 $\beta$-MO-induced phenotype, and vice versa (Table 1). This evidence clearly demonstrates that two isoforms of GSK3 are necessary for heart development, but the function of GSK3 $\alpha$ and GSK3 $\beta$ is not redundant, suggesting that GSK3 $\alpha$ and GSK3 $\beta$ play specific roles in cardiogenesis during zebrafish development.

We injected either $g s k 3 \alpha$ - or gsk3 $\beta$-MO into embryos derived from the transgenic line $\operatorname{Tg}(c m l c 2: g f p)$, in which the GFP is expressed specifically in heart, resulting in a good material to monitor cardiac development of zebrafish [29]. In the wild-type embryos, the heart precursor cells completed their in situ formation, elongated, and jogged to the left at $24 \mathrm{hpf}$; started looping at $30 \mathrm{hpf}$; and completed looping at $48 \mathrm{hpf}$ [34]. However, we observed that heart development was retarded, failing to elongate at $24 \mathrm{hpf}$ (Fig. 3B) and even ceasing at heart-cone stage without further morphogenesis to a heart tube at [30-36] hpf (Figs. 3E, H) in the gsk3 $\alpha$-MO-injected embryos. We observed defective hearts as stretched to a thin and stringlike shape at $72 \mathrm{hpf}$ (Fig. 3L). Nevertheless, unlike in gsk3 $\alpha$ morphants, elongation of the heart tube in gsk3 $\beta$ morphants at $24 \mathrm{hpf}$ was as normal as in wild-type zebrafish (Fig. 3C), but heart looping was incomplete from 30 to $36 \mathrm{hpf}$ (Figs. 3F, I), resulting in a stretched heart at $72 \mathrm{hpf}$ (Fig. 3M).

In addition, we have designed to an experiment for using a standard negative control morpolino (MO) injection: $5^{\prime}-$ CCTCTTACCTCAGTTACAATTTATA-3' (Gene Tools, USA). This oligo has no target, no significant biological activity. After 2 and 6 ng of this control MO were injected, no any defects were observed at $24 \mathrm{hpf}$. The morphology and development of heart appeared normally (see Additional file 1 and Figure $3 \mathrm{~N}$ ). These results reveal that the defects induced by the $g s k 3 \alpha$ - and $g s k 3 \beta$-MO are specific in this study.

\section{Effect of GSK3 on the number of cardiomyocytes is isoform-specific}

Compared to that of wild-type and $g s k 3 \beta$ morphants, the GFP signals in cardiomyocytes of gsk $3 \alpha$ morphants were greatly reduced (Fig. 3B). To investigate whether the reduced GSK3 $\alpha$ level affects the cardiomyocyte number, we used a cardiomyocyte marker, cardiac myosin light chain 2 (cmlc2), to detect cells at heart-field and heartcone stages. We found that the number of $\mathrm{cmlc2}$-positive cells was greatly reduced in $g s k 3 \alpha$ morphants at both heart-field and heart-cone stages (Fig. 4B, E), indicating that the cardiomyocyte number was greatly reduced in the gsk3 $\alpha$ morphants. These results suggest that the retarded heart development in $g s k 3 \alpha$ morphants is due to the 

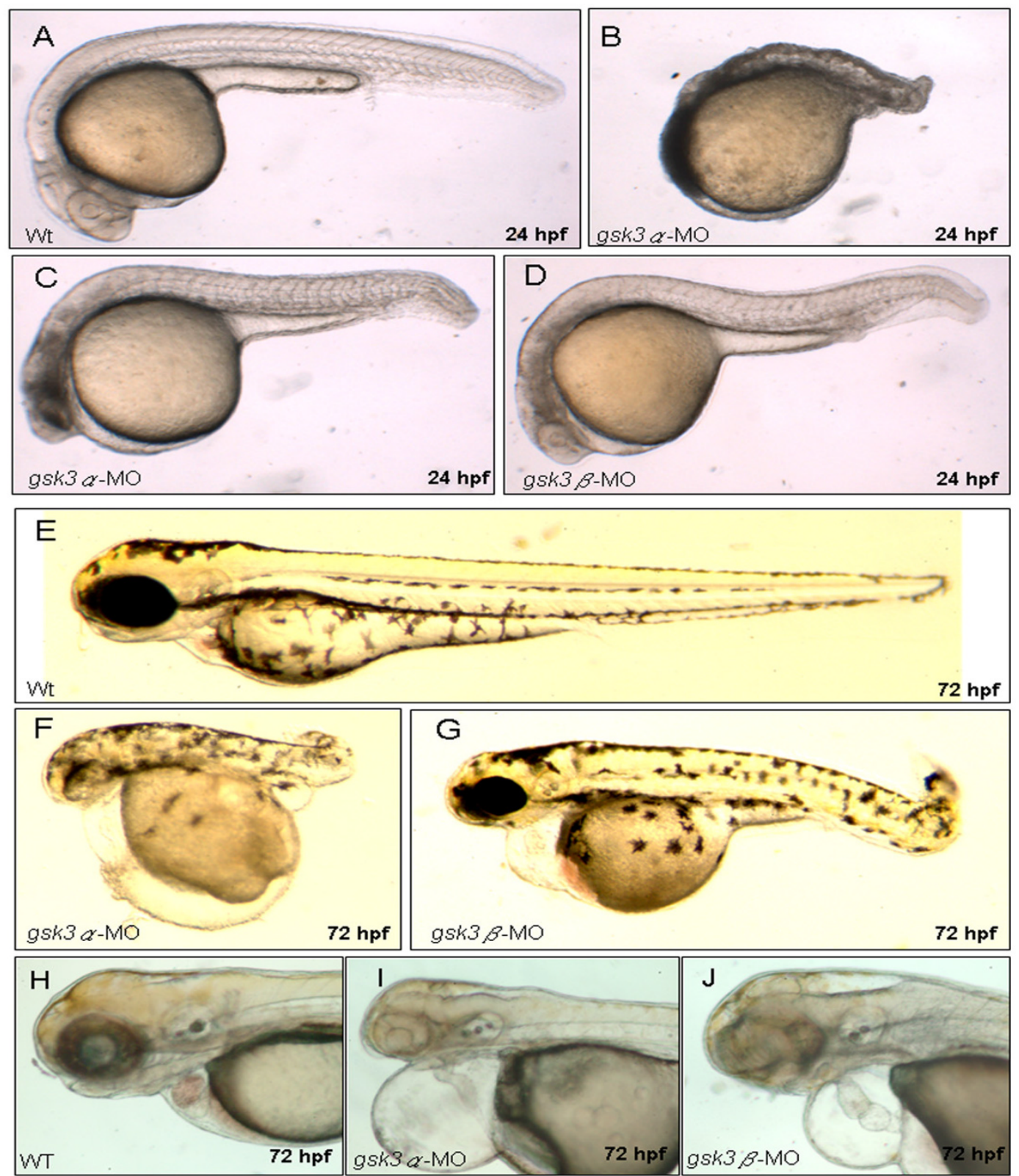

\section{Figure 2}

The morphological defects in gsk $3 \alpha$ and gsk $3 \beta$ morphants. Wild-type embryos (A, E, H), gsk $3 \alpha(\mathrm{B}, \mathrm{C}, \mathrm{F}, \mathrm{I})$, and gsk3 $\beta$ (D, G, J) morphants. The 24 hpf gsk $3 \alpha$ morphants have mild (C) to severe (B) defects in axis formation. At 72 hpf, both gsk3 $\alpha$ and gsk $3 \beta$ morphants displayed pericardial edema (F, G, I, J) and an unlooped, stretched heart (I, J). 
Table I: Morphological phenotypes of zebrafish embryos derived from fertilized eggs injected with different materials

\begin{tabular}{|c|c|c|c|c|}
\hline Injected materials & Concentration & $\begin{array}{l}\text { Number of embryos } \\
\text { surviving among number of } \\
\text { injected eggs }\end{array}$ & Wild-type phenotype & $\begin{array}{l}\text { Abnormal Heart } \\
\text { Development }\end{array}$ \\
\hline gsk3 $\alpha-\mathrm{MO}$ & $0.5 \mathrm{ng}$ & $146 / 155(94.2 \%)$ & $85(58.2 \%)$ & $61(41.8 \%)$ \\
\hline gsk3 $\alpha-M O$ & I ng & $176 / 191$ (92.1\%) & $61(34.6 \%)$ & 115 (65.4\%) \\
\hline gsk3 $\alpha-M O$ & $2 \mathrm{ng}$ & $212 / 273(77.7 \%)$ & $25(11.8 \%)$ & I87 (88.2\%) \\
\hline gsk3 $\beta-\mathrm{MO}$ & $2 \mathrm{ng}$ & $126 / 129(97.7 \%)$ & $88(69.8 \%)$ & $38(30.2 \%)$ \\
\hline gsk3 $\beta-\mathrm{MO}$ & $4 \mathrm{ng}$ & $137 / 144$ (95.1\%) & $69(50.4 \%)$ & $68(49.6 \%)$ \\
\hline gsk3 $\beta-\mathrm{MO}$ & $6 \mathrm{ng}$ & $288 / 3 \mid 4(91.7 \%)$ & $36(12.5 \%)$ & 252 (87.5\%) \\
\hline $\operatorname{axin} I-M O$ & $6 \mathrm{ng}$ & $151 / 164(92.1 \%)$ & $27(17.9 \%)$ & $124(82.1 \%)$ \\
\hline dsRed mRNA & $100 \mathrm{pg}$ & $68 / 68(98.8 \%)$ & $83(100 \%)$ & $0(0 \%)$ \\
\hline Control MO & $2 \mathrm{ng}$ & $105 / 108(97.2 \%)$ & $101(96.2 \%)$ & $4(3.8 \%)$ \\
\hline Control MO & $6 \mathrm{ng}$ & $112 / 125(89.6 \%)$ & $103(93.6 \%)$ & 7 (6.4\%) \\
\hline gsk3 $\alpha$-mRNA_gsk3 $\alpha-M O$ & $50 \mathrm{pg}+2 \mathrm{ng}$ & $59 / 69(85.5 \%)$ & $18(30.5 \%)$ & $4 \mathrm{I}(69.5 \%)$ \\
\hline gsk $3 \alpha-$ mRNA_gsk $3 \alpha-M O$ & $100 p g+2 n g$ & $93 / 118(78.8 \%)$ & $51(54.8 \%)$ & $42(45.2 \%)$ \\
\hline gsk3 $\beta$-mRNA_gsk3 $\alpha-M O$ & $50 p g+2 n g$ & $72 / 90(80.0 \%)$ & $9(12.5 \%)$ & $63(87.5 \%)$ \\
\hline gsk3 $\beta$-mRNA_gsk3 $\alpha-M O$ & $100 p g+2 n g$ & $91 / 134(67.2 \%)$ & $5(5.5 \%)$ & $86(94.5 \%)$ \\
\hline gsk $3 \beta$-mRNA_gsk $3 \beta-M O$ & $50 p g+6 n g$ & $73 / 77$ (94.8\%) & $45(61.6 \%)$ & $28(38.4 \%)$ \\
\hline gsk3 $\beta$-mRNA_gsk3 $\beta-\mathrm{MO}$ & $100 \mathrm{pg}+6 \mathrm{ng}$ & $128 / \mid 44(89.0 \%)$ & $96(75.0 \%)$ & $32(25 \%)$ \\
\hline gsk3 $\alpha$-mRNA_gsk3 $\beta-M O$ & $50 p g+6 n g$ & $83 / 109$ (76.1\%) & $15(18.1 \%)$ & 68 (81.9\%) \\
\hline gsk3 $\alpha$-mRNA_gsk3 $\beta-M O$ & $100 p g+6 n g$ & $92 / 127(72.4 \%)$ & $8(8.7 \%)$ & $84(91.3 \%)$ \\
\hline dsRed-mRNA_gsk3 $\alpha-M O$ & $100 p g+2 n g$ & $83 / 96(86.5 \%)$ & $7(8.4 \%)$ & 76 (91.6\%) \\
\hline dsRed-mRNA_gsk3 $\beta-M O$ & $100 p g+6 n g$ & $75 / 82(91.4 \%)$ & $13(17.3 \%)$ & $62(82.7 \%)$ \\
\hline
\end{tabular}

Fertilized eggs were injected at the I-cell stage, and then gsk $3 \alpha$ morphants were observed at 36 to $48 \mathrm{hpf}$; gsk $3 \beta$ morphants were observed the heart positioning at 24 to $36 \mathrm{hpf}$. Results are from three independent experiments. dsRed mRNA: served as a negative control.

decreased number of cardiomyocytes during early cardiogenesis. In contrast, gsk $3 \beta$ morphants displayed normal cmlc2 staining (Fig. 4C, F), indicating that cardiomyocyte number remains unchanged in $g s k 3 \beta$ morphants. These results also clearly demonstrate that GSK3 $\alpha$ and GSK3 $\beta$ play distinct roles during cardiogenesis.

\section{Apoptosis occurs in the head of gsk $3 \alpha$ knockdown embryos}

The pronounced degeneration in the head of $g s k 3 \alpha$ morphants at [18-30] hpf were also observed (Fig. 2C). To confirm whether the reduced cardiomyocyte number in $g s k 3 \alpha$ morphants was due to apoptosis, the embryos were analyzed by Terminal deoxynucleotidyl Transferase Biotin-dUTP Nick End Labeling (TUNEL) assay after MO injection. In wild-type embryos at $20 \mathrm{hpf}$, apoptosis was low (Fig. 4G). However, in $g s k 3 \alpha$ morphants at the same stage, apoptosis was pronounced throughout the axis, especially in the head (Fig. $4 \mathrm{H}$ ) but was limited in the head of controls (G) and gsk $3 \beta$ morphants (I). Moreover, In gsk3a-morphants, the GFP signal was very faint at 24 hpf (Fig. 4N). The apoptotic signals were co-localized with the heart-specific GFP signal, indicating that the reduced cardiomyocyte numbers was due to apoptosis in heart (Fig. 4O). Taken together, the heart defects in gsk3 $\alpha$ morphants was due to the reduced number of cardiomyocytes, which results from apoptosis in the head.

\section{GSK3 $\beta$, but not GSK3 $\alpha$, is involved in the cardiac positioning}

Although the heart of $g s k 3 \beta$-MO-injected embryos eventually becomes a string-like shape, we found that the cardiomyocyte development was not affected in the gsk3 $\beta$ morphants during early cardiac development, suggesting that GSK3 $\beta$ may play a unique role in cardiac morphogenesis. Whole-mount in situ hybridization of the $\mathrm{cmlc2}$ probe at $36 \mathrm{hpf}$, outlining cardiac looping, was marked by a rightward bending in the ventricle in wild-type embryos (Fig. 5A). However, no looping was observed in gsk3 $\beta$ morphants (Fig. 5B-D). Upon detailed analysis of the early (jogging) and late (looping) stages of cardiac positioning in the gsk $3 \beta$ morphant heart (Table 2), we found that heart positioning was severely disrupted in $g s k 3 \beta$ morphants and that the extent of the defect was proportional to the amount of $g s k 3 \beta$-MO we injected. The majority of $g s k 3 \beta$ morphant hearts failed to jog $(69.9 \% ; 65 / 93)$. Moreover, this defect was frequently accompanied by no looping (45.3\%) or L-looping (14.4\%) of the heart tube, compared to wild-type, which has correct left-jogging (93.1\%; 67/72) and D-looping (92.4\%; 122/132). These results indicate that knockdown of GSK3 $\beta$ resulted in a severe disruption of jogging and looping of cardiac positioning. However, we found that the ventricle-specific marker $v m h c$ and the atrium-specific marker amhc were normally transcribed in $g s k 3 \beta$ morphants (Fig. $5 \mathrm{E}$, G vs. $5 \mathrm{~F}, \mathrm{H})$, suggesting that GSK3 $\beta$ might not affect the cham- 

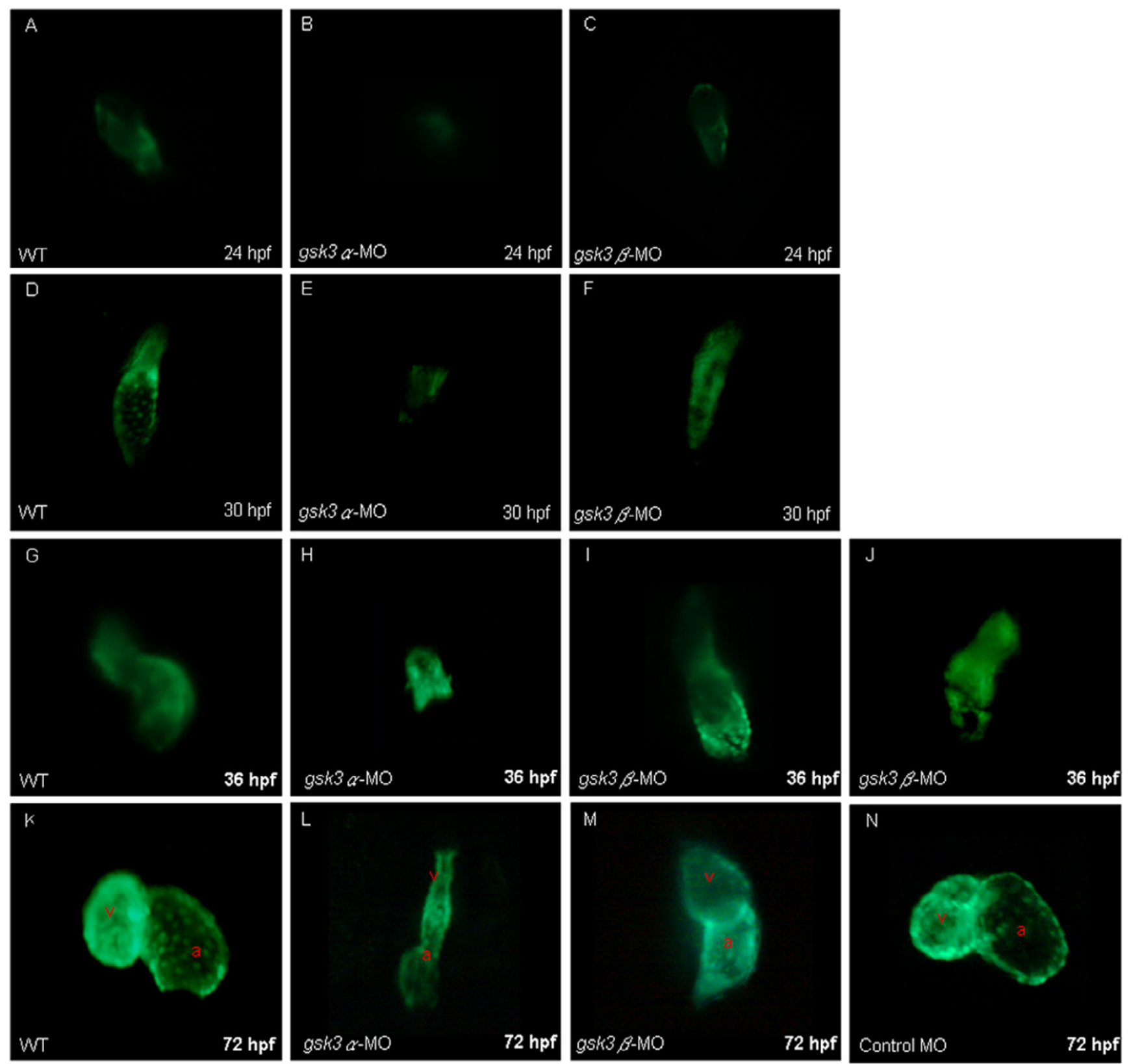

Figure 3

The cardiac defects induced by the knockdown of zebrafish GSK3 $\alpha$ and GSK3 $\beta$. Anti-sense morpholino oligonucleotide (MO), which was designed to specifically inhibit the translation of either gsk $3 \alpha$-(gsk $3 \alpha$-MO) or gsk $3 \beta$-mRNA (gsk3 $\beta$ MO), was injected into one-celled stage embryos and the heart morphology was observed at the stage as indicated. The elongation of heart tube was normally developed at $24 \mathrm{hpf}$ in the wild-type $(\mathrm{A})$ and in the gsk $3 \beta$ morphants $(\mathrm{C})$; whereas the heart of gsk3 $\alpha$ morphant did not elongate to from a heart-tube (B). The wild-type (D) and gsk3 $\beta$ morphant's heart (F) developed normally at $30 \mathrm{hpf}$, but the heart of gsk3 $\alpha$ morphant was still retardant development at $30 \mathrm{hpf}(\mathrm{E})$, and even ceased at heartcone stage at $36 \mathrm{hpf}(\mathrm{F})$. Compared to the wild-type $(\mathrm{G})$, however, the heart positioning was abnormally in the gsk3 $\beta$ morphant at $36 \mathrm{hpf}(\mathrm{I}, \mathrm{J})$. Eventually, both gsk $3 \alpha$ and gsk3 $\beta$ morphants displayed an unlooped and stretched heart (L, M). The heart morphology of embryos injected with the control MO was also observed at $72 \mathrm{hpf}(\mathrm{N})$. a: atrium; v: ventricle. 


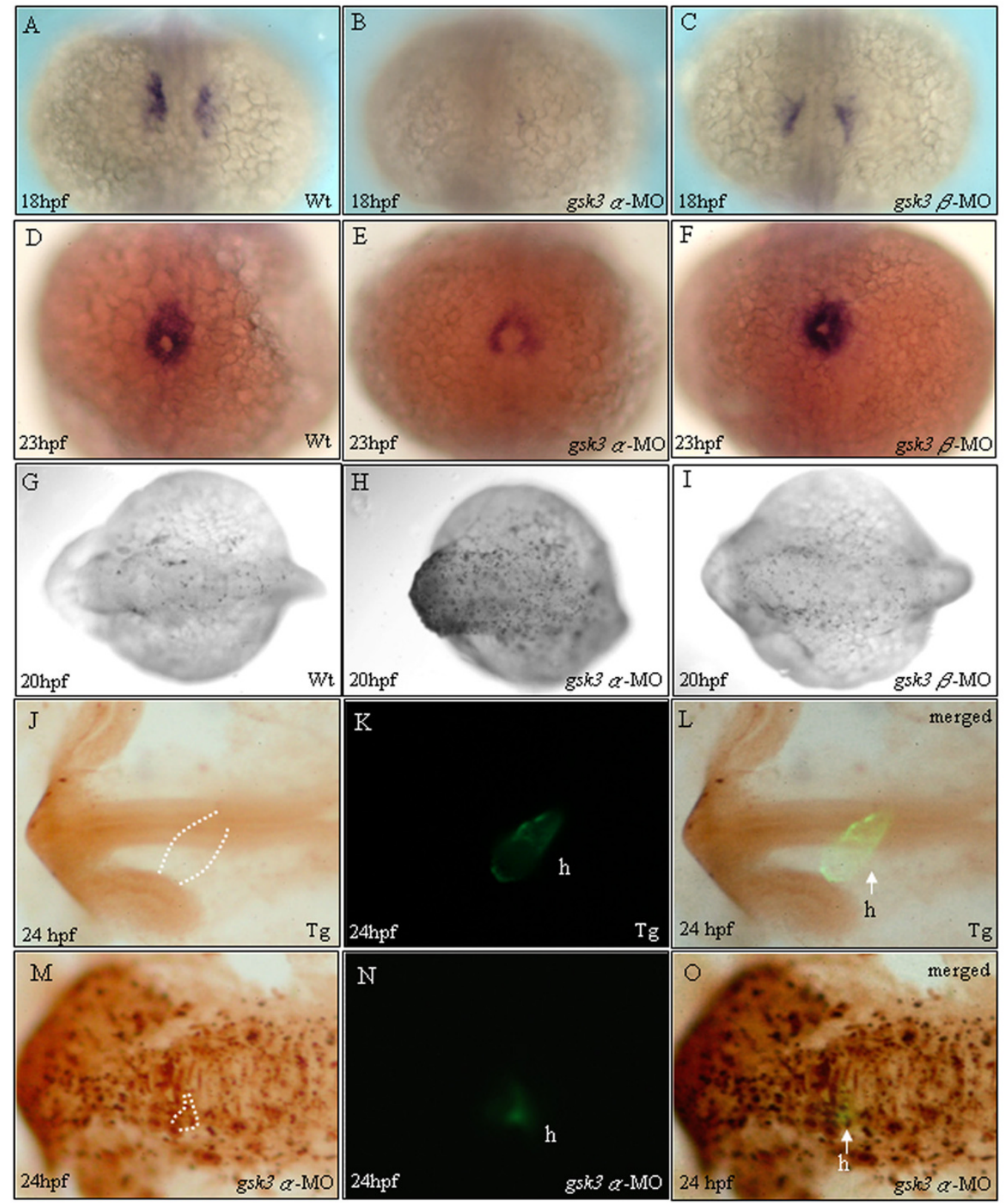

\section{Figure 4}

The heart defects in gsk3 $\alpha$ morphants weredue to a reduced cardiomyocyte population size. Dorsal (A-I) and lateral (J-O) views of embryos stained by in situ hybridization (A-F) and TUNEL assay (G-L). Whole mount in situ hybridization staining with cmlc 2 at 18 and $23 \mathrm{hpf}$ received that gsk $\alpha$-MO causes a repressive influence on cardiomyocyte formation (B, E). The heart defect in gsk $3 \alpha$ morphants was due to the reduction of cardiomyocyte population size. However, gsk $3 \beta$ morphants display normal cardiomyocyte formation (C, F) compared to wild-type embryos (A, D). TUNEL labeling was evident throughout the head of gsk3a-MO-injected embryos $(\mathrm{H})$, especially in the head, but was limited in the head of controls $(\mathrm{G})$ and gsk3 $\beta$ morphants (I). Compared to embryos derived from the transgenic line, $\mathrm{Tg}(\mathrm{cmlc2}$ :EGFP), which has heart-specific GFP (K), we observed that the heart of gsk3 $\alpha$ morphant did not elongate to form a heart-tube and the GFP signal was very faint at 24 hpf $(N)$. Panels $L$ and $O$ are the merged images from $J$ and $K$, and $M$ and $N$, respectively. The apoptotic signals were co-localized with the heart-specific GFP signal, indicating that the reduced cardiomyocyte numbers was due to apoptosis in heart $(\mathrm{O})$. h: heart. 
ber-specific pattern of gene expression, although normal heart looping was not completed. We also noted that the heart positioning in $g s k 3 \alpha$ morphants was delayed but that correct jogging (left-jog) and looping (D-loop) were observed at [36-48] hpf, indicating that GSK3 $\alpha$ was not involved in heart positioning.

\section{GSK3 $\beta$ mediates bmp4 and lefty-I in cardiac positioning and is required for left-right patterning}

Cardiac bmp4 is an integral component involved in the asymmetric signaling pathway and interprets left-right information for the zebrafish embryo heart [35]. The bmp4 transcripts became markedly asymmetric, with far more on the left side than on the right side of the heart ring at $20 \mathrm{hpf}$ (Fig. 6A, B), just before jogging. This leftpredominant asymmetry persists through the stages of jogging (25 hpf, Fig. 6G). However, the pattern of bmp4 expression in $g s k 3 \beta$ morphants was symmetrical before jogging (Fig. 6D, E) and ectopic around the heart-tube stage at $25 \mathrm{hpf}$, thereby disrupting the pattern of left-predominant asymmetry (Fig. 6H, I). Moreover, another asymmetric marker, lefty-1 [36], lost its expression domain in the left side of the midline in $g s k 3 \beta$ morphants (Fig. 6C, F). We propose that GSK3 $\beta$ mediates bmp4 and lefty-1 in cardiac positioning.

\section{GSK3 $\beta$ modulates valve formation and heart position through Wnt/ $\beta$-catenin signaling}

Many morphological defects of heart were found in the gsk $3 \beta$-MO-injected zebrafish embryos. Moreover, when we used the valve markers $b m p 4$ and versican to detect the gsk3 $\beta$-MO-injected embryos at $60-72 \mathrm{hpf}$, we found that these valve markers were markedly up-regulated in the heart (Fig. 7A-D), suggesting that GSK3 $\beta$ might also be involved in the formation of cardiac valves. Thus, we used a two-photon fluorescence image to directly observe the valve formation of embryos derived from the transgenic zebrafish line $\operatorname{Tg}(\mathrm{cmlc2}$ :Hc-RFP; 28). The yellow color shown in our nonlinear microscopy image (valves and red blood cells) is corresponding to the image modality taken by the Third-Harmonic-Generation Microscopy. Valves were normally formed in the wild-type embryos (Fig. 7E), but valves of embryos injected with $g s k 3 \beta$-MO were totally absent (Fig. 7F).

Hurlstone et al [37] reported that cardiac valve formation is severely affected in zebrafish APC mutants ( $a p c^{m c r}$ ). Furthermore, when axin1, another key component in the Wnt pathway, is knocked down, either a reduction or absence of heart positioning of the heart tube was frequently observed (see Additional file 2A-D). GSK3 is known to be important in the canonical Wnt pathway, and the defective valves and hearts in gsk3 $\beta$-MO-injected embryos were identical to those observed in the apc ${ }^{\text {mor }}$ mutants and axin1 morphants, suggesting that GSK3 $\beta$ modulates cardiac development through Wnt/ $\beta$-catenin signaling.

\section{Discussion}

GSK3 $\beta$ knockout mice display an embryonic lethal phenotype, indicating that GSK3 $\alpha$ does not compensate for the loss of GSK3 $\beta$ [9]. Furthermore, the activity of GSK3 $\alpha$, but not GSK3 $\beta$, is required for the production of amyloid$\beta$ in the brain of patients with Alzheimer's disease [38]. All these findings indicate that there may be isoform-specific functions of GSK3, although they exhibit similar biochemical and substrate properties in vitro [7]. However, to clearly delineate the biological functions of these two GSK3 isoforms in vivo is difficult and little reported. In this report, we study the roles of GSK3 $\alpha$ and GSK3 $\beta$ in the cardiogenesis of zebrafish using a loss-of-function approach. The loss of either GSK3 $\alpha$ or GSK3 $\beta$ results in abnormal development of heart. Yet, the role that GSK3 plays in cardiogenesis is in an isoform-specific manner. GSK3 $\alpha$ plays a role in the survival of cardiomyocytes, whereas GSK3 $\beta$ plays a role in heart left-right biased positioning, modulated through the $\mathrm{Wnt} / \beta$-catenin signaling pathway.

\section{GSK3 $\alpha$ and GSK3 $\beta$ play different roles during zebrafish embryogenesis}

Although, knockdown of gsk $3 \alpha$ and gsk $3 \beta$ causes similar defective phenotypes, such as an unlooped and stretched heart, pericardial edema, blood pooling. We used gsk $3 \alpha$ $\mathrm{MO}$ and $g s k 3 \beta-\mathrm{MO}$ in the transgenic zebrafish line $\mathrm{Tg}(\mathrm{cmlc2}: \mathrm{GFP})$, in which GFP is expressed in the myocardium specifically, to modulate and observe, in real-time, the different defective phenotypes. The hearts of $g s k 3 \alpha$ morphants failed to elongate at $24 \mathrm{hpf}$. We prove that the heart defects induced by the gsk $3 \alpha-\mathrm{MO}$ are due to a decreased number of cardiomyocytes. On the other hand, the gsk3 $\beta$-MO-injected embryos develop normally before the onset of cardiac jogging. Defective heart positioning is observed after $26 \mathrm{hpf}$. Rescue experiments revealed that GSK $3 \alpha$ and GSK $3 \beta$ do not function redundantly. Taken together, we conclude that each isoform of GSK3 plays its own distinct role during cardiogenesis of zebrafish.

\section{GSK3 $\alpha$, but not GSK3 $\beta$, is involved in apoptosis during early embryogenesis}

GSK3 plays an important role in the regulation of apoptosis/cell survival through the activation of caspase 3 $[39,41,42]$. These findings support a role of GSK3 $\beta$ in controlling apoptosis. Many studies reporting the affect of GSK3 $\beta$ on apoptosis have been confirmed by using GSK3 inhibitors, including lithium, the first known inhibitor, and many synthetic ones [43-45]. However, these inhibitors have many effects on cells and are not isoform-specific. Thus, whether GSK3 $\alpha$ and GSK3 $\beta$ function redundantly or distinctly on cell survival is still ambiguous. In our study, extensive apoptosis is observed 

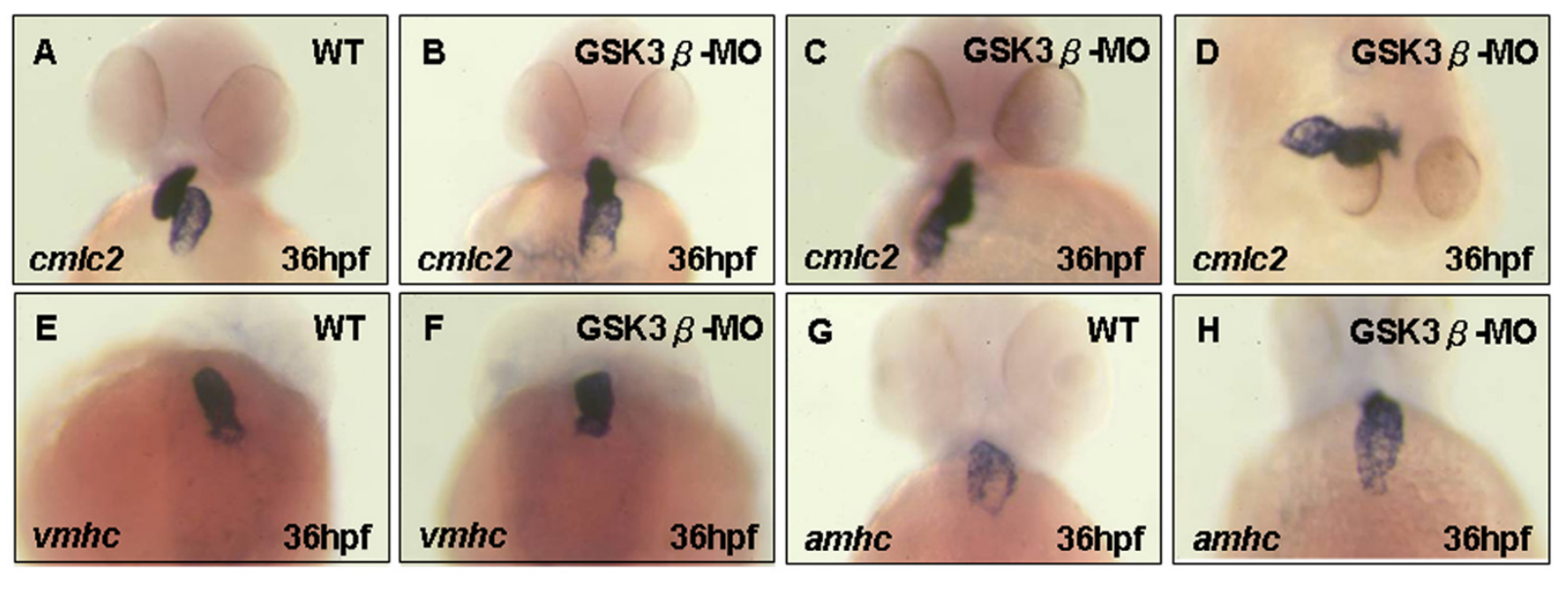

\section{Figure 5}

Cardiac positioning is gsk3 $\beta$-dependent, but the chamber-specific patterning is not. A-C, E-H) ventral view, (D) dorsal view of wild-type $(A, E, G)$, and gsk $\beta$ morphants $(B-D, F, H)$ at 36 hpf. in situ hybridization with cmlc2 staining revealed that randomized looping was observed in gsk3 $\beta$ morphants (B-D). The expression of vmhc $(F)$ and amhc $(H)$ appeared normal in gsk $3 \beta$ morphants.

throughout the head region in the gsk $3 \alpha$ morphants. On the other hand, only slight apoptosis is noticed in the gsk $3 \beta$ morphants, suggesting that GSK $3 \alpha$, but not GSK3 $\beta$, is greatly involved in apoptosis during early embryogenesis. Moreover, embryos that are co-injected with gsk $3 \alpha$ $\mathrm{MO}$ and $g s k 3 \beta$ mRNA do not show reduced apoptosis, suggesting that GSK3 $\alpha$ and GSK3 $\beta$ do not function redundantly in cell survival.

\section{GSK3 $\alpha$-mediated apoptosis may not be implicated in Wnt signaling}

The Wnt signaling are involved in cell proliferation and in apoptosis [46-49]. On the other hand, PKB/Akt, a major regulator of GSK3, also triggers a network that regulates cell cycle progression through inactivation of GSK3 $\beta$ [50].
It has been shown that $\mathrm{PKB} /$ Akt promotes cell survival in cardiac myocytes [51,52]. In zebrafish, apc ${ }^{m c r}$ mutant's hearts are morphologically normal during early cardiogenesis, but they fail to undergo looping morphogenesis [37]. Both $a p c^{m c r}$ and axin 1 mutants $(\mathrm{mbl})$ display cardiac defects that are similar to those of $g s k 3 \beta$ morphants. However, no information is provided about apoptosis in apcm and $m b l$ mutants. In this report, we find that apoptosis occurs in the head of $g s k 3 \alpha$ morphants. In addition, the axin1-MO-injected embryos and the mbl mutant of zebrafish have defects of looping morphogenesis in the heart, which are similar to defects occurring in the gsk3 $\beta$ morphants but are unlike defects occurring in the $g s k 3 \alpha$ morphants (see Additional file 2). Therefore, we know that GSK3 $\alpha$ may not mediate apoptosis implicated in Wnt

Table 2: Knockdown GSK3 $\beta$ levels that disrupt normal cardiac jogging and looping

\begin{tabular}{|c|c|c|c|c|c|c|c|c|}
\hline & No. of embryos & Left-jog & No-jog & Right-jog & No. of embryos & D-loop & No-loop & L-loop \\
\hline Uninjected & 72 & $93 \%$ & $2.8 \%$ & $4.2 \%$ & 132 & $92.5 \%$ & $3 \%$ & $4.5 \%$ \\
\hline $2 \mathrm{ng}$ gsk3 $\alpha-\mathrm{MO}$ & 63 & $87.3 \%$ & $7.9 \%$ & $4.8 \%$ & 74 & $93.2 \%$ & $4.1 \%$ & $2.7 \%$ \\
\hline I ng gsk3 $\alpha-\mathrm{MO}$ & 58 & $93.1 \%$ & $5.2 \%$ & $1.7 \%$ & 90 & $94.5 \%$ & $2.2 \%$ & $3.3 \%$ \\
\hline $6 \mathrm{ng}$ gsk $3 \beta-\mathrm{MO}$ & 93 & $17.2 \%$ & $69.9 \%$ & 12.95 & 159 & $40.3 \%$ & $45.3 \%$ & $14.4 \%$ \\
\hline $4 \mathrm{ng}$ gsk $3 \beta-\mathrm{MO}$ & 86 & $22.1 \%$ & $67.4 \%$ & $10.5 \%$ & 101 & $40.6 \%$ & $44.6 \%$ & $14.8 \%$ \\
\hline $2 \mathrm{ng}$ gsk $3 \beta-\mathrm{MO}$ & 62 & $45 \%$ & $50 \%$ & $5 \%$ & 107 & $70.1 \%$ & $22.4 \%$ & $7.5 \%$ \\
\hline
\end{tabular}

gsk3 $\alpha$ morphants were analyzed for heart positioning at 36 to 48 hpf; gsk3 $\beta$ morphants were analyzed for heart positioning at 24 to 36 hpf. 
signaling because apoptotic signals do not increase in axin1 morphants (data not shown). It is worth studying which pathway is implicated in GSK3 $\alpha$-mediated apoptosis.

\section{gsk $3 \beta$ regulates bmp4 during cardiac development through Wnt/ $\beta$-catenin signaling}

The phenotypes of apc $c^{m c r}$ and $m b l$ mutants are similar to our results in that inhibition of GSK3 $\beta$ also causes unlooping heart tube, pericardial edema, and blood pooling [37]. In addition, valve development is totally lost in gsk $3 \beta$ morphants (Fig. 7), which is similar to that of $a p c^{m c r}$ mutants. Ectopic expression of $b m p 4$ in the heart at 24-72 hpf and ectopic expression of versican in the valve at 60$72 \mathrm{hpf}$ are also observed in the apc ${ }^{m c r}$ mutant and in the gsk $3 \beta$ morphant (Figs. 7A-D). Moreover, the retention of bmp4 symmetry is associated with disordered jogging, and we observe that $b m p 4$ retention occurred in the gsk $3 \beta$ morphant. In addition, $b m p 4$ is downstream of Wnt $/ \beta$-catenin signaling in several systems $[53,54]$. Therefore, it is reasonable to conclude that GSK3 $\beta$ might regulate zebrafish cardiac development by means of the canonical Wnt $/ \beta$ catenin signaling pathway.

\section{GSK3 $\beta$ may be involved in the regulation of T-box genes during cardiogenesis}

Our study reveals that knockdown of $g s k 3 \beta$ causes a stringlike heart. This phenotype is similar to the heartstrings mutant, caused by mutation of the tbx5 [55]. Patients with Holt-Oram syndrome, one of the autosomal dominant human "heart-hand" disorders, are caused by mutations of $t b x 5$ [56]. Both loss and gain of $t b x 5$ functions result in an absence of heart looping and an alteration in cardiacspecific genes $[57,58]$. In our study, we demonstrate that gsk $3 \beta$ morphants appear to have multiple heart defects, such as a non-looping or reversed looping heart, slower heart rate, and no blood circulation (Figs. 3, 4). In addition, after we probe with fin markers, we prove that the pectoral fin of the GSK3 $\beta$ morphant fails to differentiate (see Additional file 3). In chick, Tbx5 and Tbx4 trigger limb initiation through activation of the Wnt/Fgf signaling cascade [59]. Therefore, we propose that GSK3 $\beta$ and Tbx5 might be involved in the same regulatory mechanism during cardiogenesis.

\section{Zebrafish is an alternative, promising model animal to study GSK3-specific inhibitors in vivo}

GSK3 is a target of prominent drugs for treating many diseases, including Alzheimer's disease and diabetes mellitus. Substrate-competitive inhibitors, which compete for the substrate binding site of the kinase, are more likely to be highly specific inhibitors. Several ATP-competitive inhibitors of GSK3 have also been defined $[17,18]$. However, the development of new drug not only requires the identification of the target, but also requires validation in an in vivo system. Recently, Atilla-Gokcumen et al., [60] performed phenotypic experiments in zebrafish embryo which is served as an in vivo experiment to analyse the functions of novel GSK3 inhibitor, organometallic reagent (R)-7. In this study, we clearly distinguish the morphological defects in zebrafish GSK3 $\alpha$ - and GSK3 $\beta$ knockdown embryos. Therefore, these findings will surely provide new criteria for the in vivo validation of potential isoform-specific inhibitors of GSK3.

\section{Different biological function of GSK3 isoform in species}

In this report, we have defined that GSK3 $\alpha$ and GSK3 $\beta$ play distinct roles during zebrafish cardiogenesis. Moreover, the defective valves and hearts in $g s k 3 \beta$-MO-injected embryos were identical to those observed in the apcmor mutants and axin 1 morphants, suggesting that GSK3 $\beta$ modulates cardiac development through $\mathrm{Wnt} / \beta$-catenin signaling. In addition, GSK3 is a critical regulator of Wnt signaling mechanism, several recent studies have shown that the components of the Wnt signaling play an important role in heart development [3]. However, heart defects are not reported in the GSK3 $\beta$-knockout mice. One of reasons is that mice GSK3 $\alpha$ might function redundantly to GSK3 $\beta$ during the heart development of mice. We also notice that the expression profiles of GSK3 $\beta$ in zebrafish and in Xenopus are different: zebrafish gsk $3 \beta$ is weakly detected until $50-60 \%$ epiboly, but Xenopus gsk $3 \beta$ is expressed strongly and constantly throughout embryogenesis $[61,62]$. Taken together, although GSK3 isoforms share highly conserved in their functional domain, the biological functions of GSK3 isoforms in different species are not identical.

\section{Conclusion}

Our data indicate that GSK3 $\alpha$ and GSK3 $\beta$ play distinct roles during zebrafish embryogenesis. GSK3 $\alpha$, but not GSK3 $\beta$, is necessary in cardiomyocyte survival; GSK3 $\beta$ plays an important role in regulating left-right biased heart positioning during the cardiogenesis in zebrafish. We also demonstrate that the cardiac valve defects observed in gsk $3 \beta$ morphants were similar to those observed in axin1 and apc ${ }^{m c r}$ mutants, suggesting that GSK3 $\beta$ modulates valve formation and heart position through Wnt $/ \beta$-catenin signaling. Finally, the defects of gsk $3 \alpha$ morphant embryos cannot be rescued by $g s k 3 \beta$ mRNA, and vice versa, demonstrating that GSK3 $\alpha$ and GSK3 $\beta$ are not functionally equivalent. Thus, we conclude that GSK3 $\alpha$ and GSK3 $\beta$ play distinct roles during zebrafish cardiogenesis.

\section{Methods \\ Zebrafish maintenance and observation}

The zebrafish $\mathrm{AB}$ strain, transgenic lines $\mathrm{Tg}(\mathrm{cmlc2}: H c-R F P)$ and $\operatorname{Tg}(\mathrm{cmlc2}: \mathrm{GFP})$ were raised and staged as previously described (28-30). The heart formation were observed 


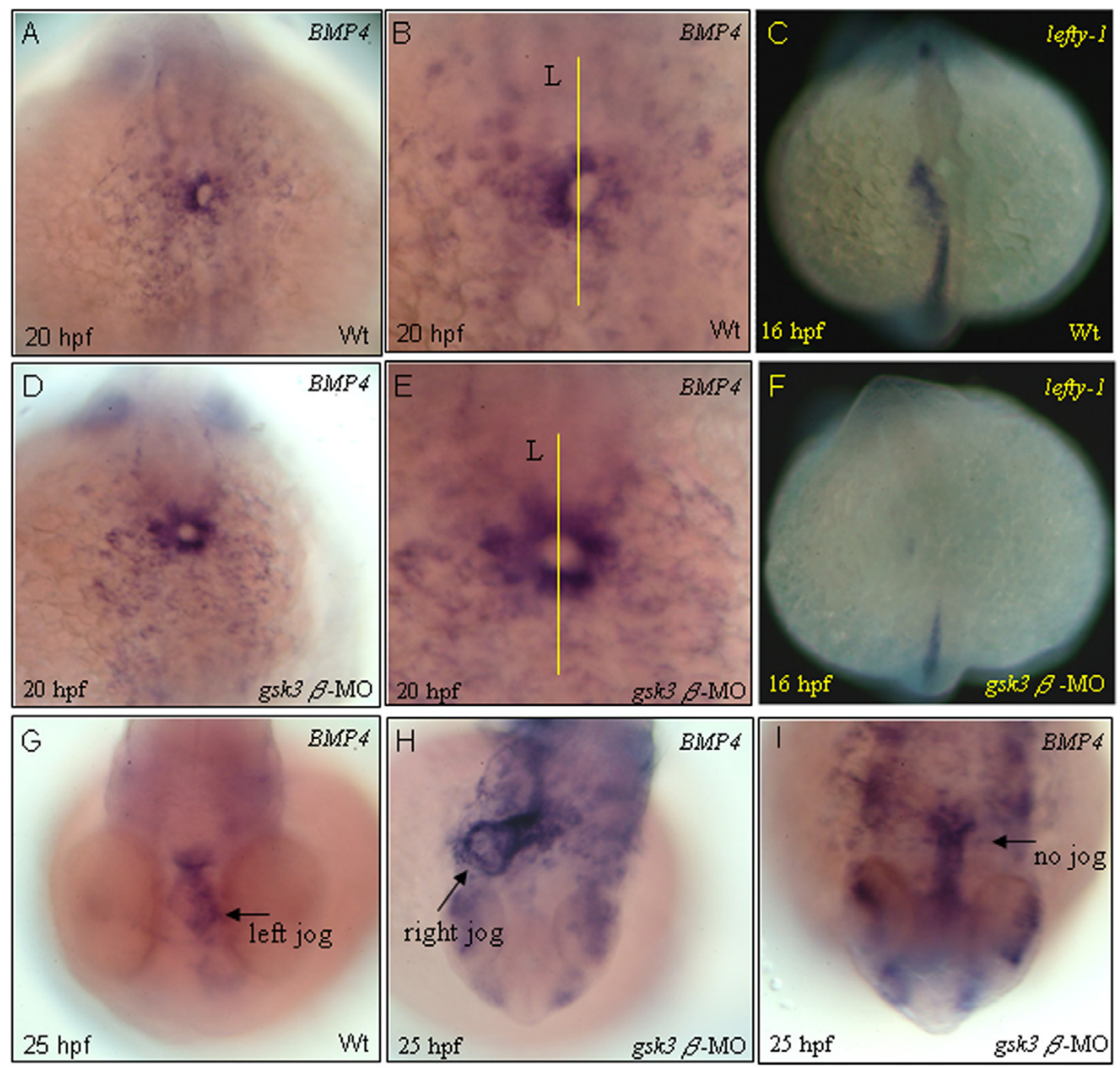

Figure 6

Heart asymmetry was affected in gsk $\mathbf{3} \beta$ morphants. Normally, bmp 4 transcripts accumulate predominantly on the left side of the heart tube at $20 \mathrm{hpf}(\mathrm{A}, \mathrm{B})$, and the left-predominant bmp4 asymmetry persists through the stages of jogging (G). However, in gsk $3 \beta$ morphants, the expression of bmp4 becomes symmetrical at $20 \mathrm{hpf}(\mathrm{B}, \mathrm{D})$. In gsk $3 \beta$ morphants, in which the heart fails to jog, bmp4 is more evenly distributed in the heart region $(\mathrm{H}, \mathrm{I})$. The left-sided lefty-I domain was greatly reduced in gsk 3 morphant hearts at $16 \mathrm{hpf}(\mathrm{F})$. All are dorsal views. $\mathrm{B}, \mathrm{E}$ are higher magnifications of $\mathrm{A}$, $\mathrm{D}$, respectively. Lines mark the midline. L, embryo left. 

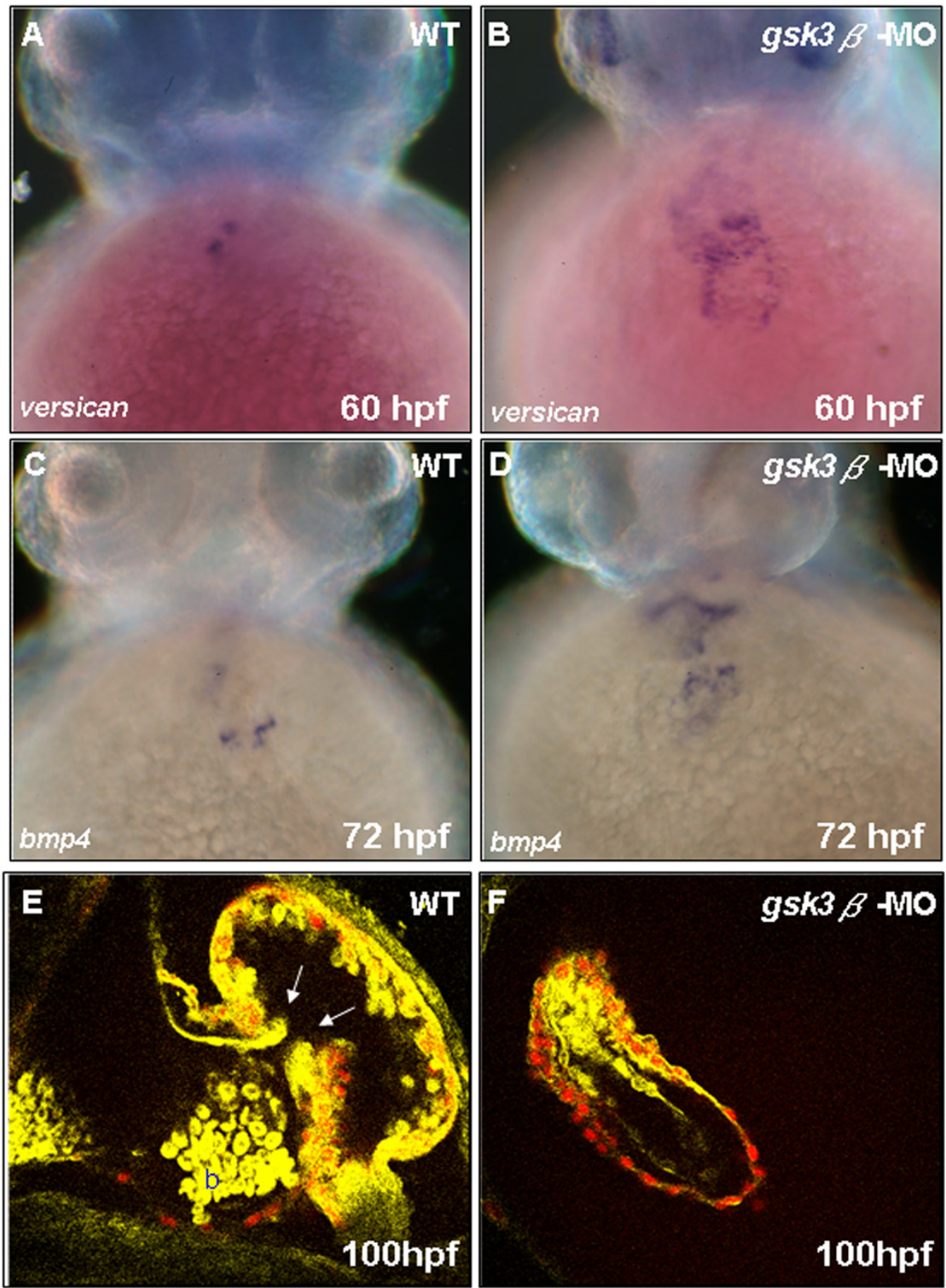

\section{Figure 7}

GSK3 $\beta$ modulates zebrafish cardiac valve formation. Whole-mount in situ hybridization with bmp4 and versican staining reveals that cardiac valve development was affected in gsk3 $\beta$ morphants. At 60-72 hpf,versican (A, B) and bmp4 (C, D) expression was greatly up-regulated in gsk $3 \beta$ morphants. $\mathrm{Tg}(\mathrm{cmlc}$ : $\mathrm{Hc}-\mathrm{RFP})$ embryos were injected with gsk3 $\beta$-MO and observed by in vivo two-photon fluorescence imaging of a live transgenic zebrafish heart at $100 \mathrm{hpf}$. The endocardial cells and blood are labeled yellow; the Hc-GFP-positive myocardial cells are labeled red. Valves are clearly observed in wild-type embryos (E; white arrows), but not in gsk $3 \beta$ morphants $(F)$. b, blood cells; $\mathrm{V}$, ventricle; $\mathrm{A}$, atrium. 
under a fluorescent stereomicroscope MZ FLIII (Leica) and two-photon fluorescence microscope and Third-Harmonic-Generation Microscopy [28].

\section{Knockdown microinjection of zebrafish embryos}

The following morpholino antisense oligonucleotides (MOs) were obtained from Gene Tools: gsk3 $\alpha-\mathrm{MO}$, CCGCTGCCGCTCATTTCGGGTTGCA; $\quad$; $k 3 \beta$-MO, GTTCTGGGCCGACCGGACATTTTTC; axin1-MO, GCTAATGCGGTCATATCTCCTCTGC; standard negative control-MO, CCTCTTACCTCAGTTACAATTTATA. All MOs were prepared at a stock concentration of $1 \mathrm{mM}$ and diluted to the desired concentration for microinjection into each embryo.

\section{Western blot}

The embryos were dechorionated and deyolked with two extra washing steps as described in Link et al. [31]. Deyolked samples were dissolved in $2 \mu \mathrm{l}$ of $2 \times$ sodium dodecyl sulfate (SDS) sample buffer per embryo and incubated for $5 \mathrm{~min}$ at $95^{\circ} \mathrm{C}$. After full-speed centrifugation for $1 \mathrm{~min}$ in a microcentrifuge to remove insoluble particles, samples were loaded on a $12 \%$ SDS gel (seven embryos per lane). Antibodies used were anti-GSK3 (Santa Cruz, SC-7291, 1:750) and anti- $\alpha$-tubulin (SigmaAldrich, T9026, 1:750).

\section{Whole-mount in situ hybridization}

Whole-mount in situ hybridization techniques have been described previously [32]. The probes were digoxigeninlabeled, after which we cloned their partial DNA fragments.

\section{mRNA preparation for the rescue experiment}

Capped mRNAs of $g s k 3 \alpha, g s k 3 \beta$, and RFP were synthesized according to the protocol of the manufacturer (Epicentre). The resultant mRNAs were diluted to $44 \mathrm{ng} / \mu \mathrm{l}$ with distilled water. Approximately $2.3 \mathrm{nl}$ was injected into one-cell stage embryos.

\section{Detection of apoptotic cell death}

The apoptosis assay was performed using The DeadEnd ${ }^{\mathrm{TM}}$ Colorimetric TUNEL System (Promega) and has been described previously [33].

\section{Authors' contributions}

HCL designed and performed all the experiments, analysis the data, and prepared the manuscript. JNT and WCC carried out the Western blot analysis; KYL, PYL and WYT took care of fish handling including morpholino injections. CCC and CKS performed the two-photon fluorescence microscope imaging; HJT was a P.I. of this project. All authors read and approved the final manuscript.

\section{Additional material}

\section{Additional file 1}

Morphological phenotypes of zebrafish embryos derived from fertilized eggs injected with standard control morpholino. The standard negative control-MO has no target, no significant biological activity, and are commonly used in many studies (Hultman et al., 2007; Besser et al., 2007; Nixon et al., 2005). After 2 and 6 ng of this control MO were injected, no any defects were observed at $24 \mathrm{hpf}$. The morphology and development of heart appeared normally.

Click here for file

[http://www.biomedcentral.com/content/supplementary/1471213X-7-93-S1.doc]

\section{Additional file 2}

Similar cardiac defects in the axin 1 and the gsk $3 \beta$ morphants. Axin1$M O$ or gsk3 $\beta-M O$ were microinjcetd to And observed under dissecting microscope by bright filed $(A, C)$ or fluorescence $(B, D)$. Incomplete looping of the heart tube was also observed in axin 1 mutant heart. Click here for file [http://www.biomedcentral.com/content/supplementary/1471213X-7-93-S2.doc]

\section{Additional file 3}

Arrested pectoral fin bud induction in gsk $3 \beta$ morphants. At $72 \mathrm{hpf}$, wildtype pectoral fins elongate (A), but gsk $3 \beta$ morphants have still not developed fin buds (arrows; D). Whole mount in situ hybridization with shh and $\mathrm{dl} \times 2$ staining reveal that the developed of fin bud were affected in gsk3 $\beta$ morphants. At 36 hpf, wild-type embryos continue shh (B) and $\mathrm{dl} 2(C)$ expression in the developing bud mesenchyme, but in gsk3 $\beta$ morphants, the shh and $\mathrm{dl} x 2$ expression is greatly decreased.

Click here for file

[http://www.biomedcentral.com/content/supplementary/1471213X-7-93-S3.doc]

\section{Acknowledgements}

We are grateful to Dr. Anna-Pavlina Haramis for providing the bmp4 and versican probes, to Drs. Christine and Bernard Thisse for providing the leftyI probe. This work was partially supported by the National Science Council, Republic of China, under grand no. NCS-95-23 I3-B-002-067-My2 (HJT), and partially supported by National Health Research Institute, grand no NHRI-EX96-920IEI (CKS).

\section{References}

I. Woodgett JR: Molecular cloning and expression of glycogen synthase kinase-3/factor A. EMBO 」 1990, 9:243-248.

2. Plyte SE, Hughes K, Nikolakaki E, Pulverer BJ, Woodgett JR: Glycogen synthase kinase-3: functions in oncogenesis and development. Biochim Biophys Acta 1992, I I I 4: 147-162.

3. Hardt SE, Sadoshima J: Glycogen synthase kinase-3beta: a novel regulator of cardiac hypertrophy and development. Circ Res 2002, 90:1055-1063.

4. van Amerongen R, Berns A: Re-evaluating the role of Frat in Wnt-signal transduction. Cell Cycle 2005, 4: 1065-1072.

5. Woodgett JR: cDNA cloning and properties of glycogen synthase kinase-3. Methods Enzymol 1991, 200:564-577.

6. Woodgett JR: Judging a protein by more than its name: GSK3. SCi STKE 200I. 200 I REI2

7. Ali A, Hoeflich KP, Woodgett JR: Glycogen synthase kinase-3: properties, functions, and regulation. Chem Rev 200I, I0I:2527-2540. 
8. Tsai JN, Lee $\mathrm{CH}$, Jeng H, Chi WK, Chang WC: Differential expression of glycogen synthase kinase 3 genes during zebrafish embryogenesis. Mech Dev 2000, 9 I:387-391.

9. Hoeflich KP, Luo J, Rubie EA, Tsao MS, Jin O, Woodgett JR: Requirement for glycogen synthase kinase-3beta in cell survival and NF-kappaB activation. Nature 2000, 406:86-90.

10. Liang MH, Chuang DM: Regulation and function of glycogen synthase kinase-3 isoforms in neuronal survival. J Biol Chem 2007, 282:3904-3917.

II. Sutherland C, Cohen P: The alpha-isoform of glycogen synthase kinase-3 from rabbit skeletal muscle is inactivated by p70 S6 kinase or MAP kinase-activated protein kinase-I in vitro. FEBS Lett 1994, 338:37-42.

12. Sutherland $C$, Leighton IA, Cohen $P$ : Inactivation of glycogen synthase kinase- 3 beta by phosphorylation: new kinase connections in insulin and growth-factor signalling. Biochem J 1993, 296: $15-19$.

13. Goode N, Hughes K, Woodgett JR, Parker PJ: Differential regulation of glycogen synthase kinase-3 beta by protein kinase $C$ isotypes. J Biol Chem 1992, 267:16878-16882.

14. Nikoulina SE, Ciaraldi TP, Mudaliar S, Mohideen P, Carter L, Henry RR: Potential role of glycogen synthase kinase-3 in skeletal muscle insulin resistance of type 2 diabetes. Diabetes 2000 , 49:263-27I.

15. Wojtaszewski JF, Nielsen P, Kiens B, Richter EA: Regulation of glycogen synthase kinase-3 in human skeletal muscle: effects of food intake and bicycle exercise. Diabetes 200I, 50:265-269.

16. Markuns JF, Wojtaszewski JF, Goodyear LJ: Insulin and exercise decrease glycogen synthase kinase-3 activity by different mechanisms in rat skeletal muscle. J Biol Chem 1999, 274:24896-24900

17. Cohen P, Goedert M: GSK3 inhibitors: development and therapeutic potential. Nat Rev Drug Discov 2004, 3:479-487.

18. Meijer L, Flajolet M, Greengard P: Pharmacological inhibitors of glycogen synthase kinase 3. Trends Pharmacol Sci 2004, 25:47I-480.

19. Bhat RV, Budd Haeberlein SL, Avila J: Glycogen synthase kinase 3: a drug target for CNS therapies. I Neurochem 2004, 89: $1313-13 \mid 7$

20. Antos CL, McKinsey TA, Frey N, Kutschke W, McAnally J, Shelton JM, Richardson JA, Hill JA, Olson EN: Activated glycogen synthase3beta suppresses cardiac hypertrophy in vivo. Proc Natl Acad Sci U S A 2002, 99:907-912.

2I. Badorff C, Ruetten H, Mueller S, Stahmer M, Gehring D, Jung F, Ihling C, Zeiher AM, Dimmeler S: Fas receptor signaling inhibits glycogen synthase kinase $3 \mathrm{~s}$ and induces cardiac hypertrophy following pressure overload. J Clin Invest 2003, 109:373-38I.

22. Haq S, Choukroun G, Kang ZB, Ranu H, Matsui T, Rosenzweig A, Molkentin JD, Alessandrini A, Woodgett J, Hajjar R, Michael A, Force T: Glycogen Synthase Kinase-3s Is a Negative Regulator of Cardiomyocyte Hypertrophy. / Cell Biol 2000, I5 I: I 17-I 29.

23. Michael A, Haq S, Chen X, Hsich E, Cui L, Walters B, Shao Z, Bhattacharya K, Kilter H, Huggins G, Andreucci M, Periasamy M, Solomon RN, Liao R, Patten R, Molkentin JD, Force T: Glycogen synthase kinase-3beta regulates growth, calcium homeostasis, and diastolic function in the heart. J Biol Chem 2004, 279:2/383-21393.

24. Foley AC, Mercola M: Heart induction by Wnt antagonists depends on the homeodomain transcription factor Hex. Genes Dev 2005, 19:387-396.

25. Harris JA, Francannet C, Pradat P, Robert E: The epidemiology of cardiovascular defects, part 2: a study based on data from three large registries of congenital malformations. Pediatr Cardiol 2003, 24:222-235.

26. Shader RI, Greenblatt DJ: Lithium and the newborn heart. / Clin Psychopharmacol 1990, 10:311.

27. Zierler S: Related Maternal drugs and congenital heart disease. Obstet Gynecol 1985, 65: I 55-165.

28. Tsai TH, Lin CY, Tsai HJ, Chen SY, Tai SP, Lin KH, Sun CK: Biomolecular imaging based on far-red fluorescent protein with a high two-photon excitation action cross section. Opt Lett 2006, $31: 930-932$

29. Huang CJ, Tu CT, Hsiao CD, Hsieh FJ, Tsai HJ: Germ-line transmission of a myocardium-specific GFP transgene reveals critical regulatory elements in the cardiac myosin light chain 2 promoter of zebrafish. Dev Dyn 2003, 228:30-40.
30. Kimmel CB, Ballard WW, Kimmel SR, Ullmann B, Schilling TF: Stages of embryonic development of the zebrafish. Dev Dyn 1995, 203:253-3।0

31. Link V, Shevchenko A, Heisenberg CP: Proteomics of early zebrafish embryos. BMC Dev Biol 2006, 6: I

32. Lee HC, Huang HY, Lin CY, Chen YH, Tsai HJ: Foxd3 mediates zebrafish myf5 expression during early somitogenesis. Dev Biol 2006, 290:359-372

33. Lin CY, Yung RF, Lee HC, Chen WT, Chen YH, Tsai HJ: Myogenic regulatory factors Myf5 and Myod function distinctly during craniofacial myogenesis of zebrafish. Dev Biol 2006, 299:594-608.

34. Stainier DY: Zebrafish genetics and vertebrate heart formation. Nat Rev Genet 200I, 2:39-48.

35. Chen JN, van Eeden FJ, Warren KS, Chin A, Nusslein-Volhard C Haffter P, Fishman MC: Left-right pattern of cardiac BMP4 may drive asymmetry of the heart in zebrafish. Development 1997. I 24:4373-4382.

36. Ramsdell AF: Left-right asymmetry and congenital cardiac defects: getting to the heart of the matter in vertebrate leftright axis determination. Dev Biol 2005, 288: I-20.

37. Hurlstone AF, Haramis AP, Wienholds E, Begthel H, Korving J, Van Eeden F, Cuppen E, Zivkovic D, Plasterk RH, Clevers H: The Wnt/ beta-catenin pathway regulates cardiac valve formation. Nature 2003, 425:633-637.

38. Phiel C], Wilson CA, Lee VM, Klein PS: GSK-3alpha regulates production of Alzheimer's disease amyloid-beta peptides. Nature 2003, 423:435-439.

39. Viatour P, Dejardin E, Warnier M, Lair F, Claudio E, Bureau F, Marine JC, Merville MP, Maurer U, Green D, Piette J, Siebenlist U, Bours V, Chariot A: GSK3-mediated BCL-3 phosphorylation modulates its degradation and its oncogenicity. Mol Cell 2004, 16:35-45.

40. King TD, Bijur GN, Jope RS: Caspase-3 activation induced by inhibition of mitochondrial complex $I$ is facilitated by glycogen synthase kinase-3beta and attenuated by lithium. Brain Res 2001, 919:106-114

4I. Song L, De Sarno P, Jope RS: Central role of glycogen synthase kinase-3beta in endoplasmic reticulum stress-induced caspase-3 activation. J Biol Chem 2002, 277:4470I-44708.

42. Stoica BA, Movsesyan VA, Lea PM 4th, Faden Al: Ceramideinduced neuronal apoptosis is associated with dephosphorylation of Akt, BAD, FKHR, GSK-3beta, and induction of the mitochondrial-dependent intrinsic caspase pathway. Mol Cell Neurosci 2003, 22:365-382.

43. Klein PS, Melton DA: A molecular mechanism for the effect of lithium on development. Proc Natl Acad Sci U S A 1996 , 93:8455-8459.

44. Eldar-Finkelman $\mathrm{H}$ : Glycogen synthase kinase 3: an emerging therapeutic target. Trends Mol Med 2002, 8: I26-I32.

45. Martinez A, Castro A, Dorronsoro I, Alonso M: Glycogen synthase kinase 3 (GSK-3) inhibitors as new promising drugs for diabetes, neurodegeneration, cancer, and inflammation. Med Res Rev 2002, 22:373-384.

46. Sommer L: Checkpoints of melanocyte stem cell development. Sci STKE 2005. 205 pe42

47. Willert K, Brown JD, Danenbergn E, Duncan AW, Weissman IL, Reya $T$, Yates JR 3rd, Nusse R: Wnt proteins are lipid-modified and can act as stem cell growth factors. Nature 2003, 423:448-452.

48. Chen S, Guttridge DC, You Z, Zhang Z, Fribley A, Mayo MW, Kitajewski J, Wang CY: Wnt-I signaling inhibits apoptosis by activating beta-catenin/T cell factor-mediated transcription. Cell Biol 200I, I 52:87-96.

49. You L, He B, Uematsu K, Xu Z, Mazieres J, Lee A, McCormick F, Jablons DM: Inhibition of Wnt-I signaling induces apoptosis in beta-catenin-deficient mesothelioma cells. Cancer Res 2004 64:3474-3478.

50. Liang J, Slingerland JM: Multiple roles of the PI3K/PKB (Akt) pathway in cell cycle progression. Cell Cycle 2003, 2:339-345.

51. Brar BK, Stephanou A, Knight R, Latchman DS: Activation of protein kinase B/Akt by urocortin is essential for its ability to protect cardiac cells against hypoxia/reoxygenation-induced cell death. I Mol Cell Cardiol 2002, 34:483-492.

52. Germack R, Griffin M, Dickenson JM: Activation of protein kinase $B$ by adenosine $A \mid$ and $A 3$ receptors in newborn rat cardiomyocytes. J Mol Cell Cardiol 2004, 37:989-999. 
53. Barrow JR, Thomas KR, Boussadia-Zahui O, Moore R, Kemler R, Capecchi MR, McMahon AP: Ectodermal Wnt3/beta-catenin signaling is required for the establishment and maintenance of the apical ectodermal ridge. Genes Dev 2003, 17:394-409.

54. Hill TP, Taketo MM, Birchmeier W, Hartmann C: Multiple roles of mesenchymal beta-catenin during murine limb patterning. Development 2006, 133:1219-1229.

55. Garrity DM, Childs S, Fishman MC: The heartstrings mutation in zebrafish causes heart/fin Tbx5 deficiency syndrome. Development 200I, I 29(19):4635-4645.

56. Li QY, Newbury-Ecob RA, Terrett JA, Wilson DI, Curtis AR, Yi CH, Gebuhr T, Bullen PJ, Robson SC, Strachan T, Bonnet D, Lyonnet S, Young ID, Raeburn JA, Buckler AJ, Law DJ, Brook JD: Holt-Oram syndrome is caused by mutations in TBX5, a member of the Brachyury (T) gene family. Nat Genet 1997, I5:2 I-29.

57. Liberatore CM, Searcy-Schrick RD, Yutzey KE: Ventricular expression of tbx5 inhibits normal heart chamber development. Dev Biol 2000, 223:169-180.

58. Bruneau BG, Nemer G, Schmitt JP, Charron F, Robitaille L, Caron S, Conner DA, Gessler M, Nemer M, Seidman CE, Seidman JG: A murine model of Holt-Oram syndrome defines roles of the T-box transcription factor Tbx 5 in cardiogenesis and disease. Cell 200I, 106:709-72I.

59. Takeuchi JK, Koshiba-Takeuchi K, Suzuki T, Kamimura M, Ogura K, Ogura T: Tbx5 and Tbx4 trigger limb initiation through activation of the Wnt/Fgf signaling cascade. Development 2003 I 30( I 2):2720-2739.

60. Atilla-Gokcumen GE, Williams DS, Bregman H, Pagano N, Meggers E: Organometallic compounds with biological activity: a very selective and highly potent cellular inhibitor for glycogen synthase kinase 3. Chembiochem 2006, 7:| 4433-|450.

61. Dominguez I, Itoh K, Sokol SY: Role of glycogen synthase kinase $3 b$ as a negative regulator of dorsoventral axis formation in Xenopus embryos. Proc Natl Acad Sci USA 1995, 92:8498-8502.

62. Pierce SB, Kimelman D: Regulation of Spemann organizer formation by the intracellular kinase Xgsk-3. Development 1995 , | 2 |:755-765.

Publish with Bio Med Central and every scientist can read your work free of charge

"BioMed Central will be the most significant development for disseminating the results of biomedical research in our lifetime. "

Sir Paul Nurse, Cancer Research UK

Your research papers will be:

- available free of charge to the entire biomedical community

- peer reviewed and published immediately upon acceptance

- cited in PubMed and archived on PubMed Central

- yours - you keep the copyright
BioMedcentral 